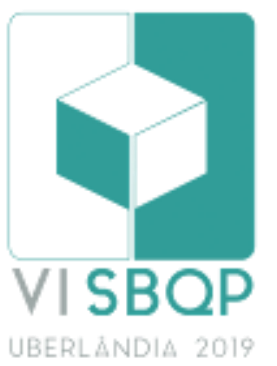

\title{
A TEMÁTICA DA HABITAÇÃO DE INTERESSE SOCIAL (HIS) NO ENSINO DE ARQUITETURA
}

\author{
MUNIZ, Andreia Fernandes \\ Universidade Vila Velha, e-mail: andreia.muniz@uvv.br \\ SOUZA, Ana Dieuzeide Santos \\ Universidade Vila Velha, e-mail: ana.souza@uvv.br \\ CUNHA, Clóvis Aquino de Freitas \\ Universidade Vila Velha, e-mail: clovis.aquino@uvv.br
}

\begin{abstract}
RESUMO
A abordagem de temas relacionados à habitação social dominou os principais debates que reuniram arquitetos e urbanistas para discutir políticas urbanas no país no último ano, com destaque para aqueles organizados pelos Conselhos de Arquitetos e Urbanistas (CAU). As propostas versam sobre a viabilidade de ampliar a atuação de arquitetos em projetos de moradias destinadas à baixa renda. Neste âmbito, verifica-se a importância de preparar os profissionais para atuarem em áreas de interesse social desde a graduação. Nesse sentido, este artigo apresenta a experiência do ensino da temática da habitação de interesse social na disciplina de Ateliê de Projetos I do curso de Arquitetura e Urbanismo da Universidade Vila Velha/ES/Brasil, cuja metodologia é aplicada à elaboração de projetos integrados de arquitetura, urbanismo e paisagismo em uma área de interesse social, tendo como fundamentação teórica conceitos relativos à proposta de criação de Zonas Especiais de Interesse Social em área consolidada, parcelamento do solo, tipologias habitacionais e habitação flexível evolutiva. Como produtos, os alunos desenvolvem os projetos de um loteamento destinado a moradia social, um parque linear e a proposta de uma tipologia habitacional que possa se adequar a um perfil familiar de baixa renda.
\end{abstract}

Palavras-chave: Habitação de Interesse Social, Habitação, Zonas Especiais de Interesse Social, Metodologia.

\begin{abstract}
The approach to issues related to social housing dominated the main debates that brought together architects and town planners to discuss urban policies in the country in the last year, especially those organized by the Councils of Architects and Town Planning (CAU). The proposals are about the feasibility of expanding the work of architects in low income housing projects. In this context, it is verified the importance of preparing professionals to work in areas of social interest since graduation. In this sense, this article presents the experience of teaching the subject of housing of social interest in the discipline of Atelier de Proyectos I of the course of Architecture and Urbanism of the University Vila Velha/ES/Brazil, whose methodology is applied to the elaboration of integrated architecture projects, urbanism and landscaping in an area of social interest, having as theoretical foundation concepts related to the proposal to create Special Zones of Social Interest in a consolidated area, land subdivision, housing typologies and flexible housing evolution. As products, the students develop the projects of a subdivision destined to social housing, a linear park and the proposal of a housing typology that can be adapted to a low income family profile.
\end{abstract}

Keywords: Social Housing, Housing, Special Zones of Social Interest, Methodology.

MUNIZ, A. F.; SOUZA, A. D. S.; CUNHA, C. A. F. A temática da Habitação de Interesse Social (HIS) no ensino de Arquitetura. In: SIMPÓSIO BRASILEIRO DE QUALIDADE DO PROJETO NO AMBIENTE CONSTRUÍDO, 6., 2019, Uberlândia. Anais... Uberlândia: PPGAU/FAUeD/UFU, 2019. p. 1462-1479. DOI https://doi.org/10.14393/sbqp19131. 


\section{INTRODUÇÃO}

A habitação popular é resultado de um processo complexo de produção com determinantes políticos, sociais, econômicos e jurídicos, que para cumprir todas as suas funções é preciso estar associada a serviços urbanos, infraestrutura urbana e equipamentos sociais (ABIKO, 1995).

O termo "habitação de interesse social" (HIS) é definida como aquela proveniente da produção de políticas públicas, efetivadas através de dispositivos legais, financiadas pelo poder público e destinadas a famílias de baixa renda.

Foi a partir de 1930 que temos o início da atuação do Estado no processo de produção da habitação de interesse social. O período marca o surgimento da habitação social (a habitação passa a ser uma questão social), com o Estado adotando uma tendência internacional de intervir no mercado de aluguéis e na produção ou financiamento de moradias (BONDUKI, 2014, p.19).

$\mathrm{Na}$ arquitetura, as discussões sobre a demanda por habitação nas cidades estiveram presentes nos três primeiros CIAM (Congressos Internacionais de Arquitetura Moderna) realizados em 1927 (Stutgart), 1929 (Frankfurt) e 1930 (Bruxelas) e influenciaram a elaboração de propostas de projetos de habitação popular racionalizadas e mínimas. $O$ ideal modernista de "habitação para o nível mínimo de vida" (Benetti, 2012, p. 24) influenciou a produção da habitação popular no país.

No final dos anos 50, a crise urbana e habitacional foi agravada pela industrialização, que acelera o crescimento da população urbana. Neste contexto, em 1963, em 1963, no Seminário de Habitação e Reforma Urbana (SHRU), organizado pelo Instituto de Arquitetos do Brasil (IAB), o tema da habitação social foi debatido amplamente por arquitetos e urbanistas, que alinhados à crise político-social da época, formularam e publicaram a primeira proposta de uma política urbana e habitacional no país.

Os loteamentos periféricos clandestinos $e$ irregulares, as favelas e a autoconstrução representam as formas de morar deste período para os mais pobres. Visando mitigar tais problemas, foi instituída a Lei federal $n^{\circ} 6.766 / 79$, que dispõe sobre o parcelamento do solo urbano.

A lei imputou responsabilidades ao loteador e ao Poder Público, ao definir parâmetros legais para o parcelamento do solo (modalidades de loteamento e desmembramento), tais como obrigatoriedade de infraestrutura básica, dimensões e área mínima do lote, existência de áreas livres de uso público/equipamentos comunitários e sistema viário. Além disso, possibilitou aos municípios regularizar os loteamentos já existentes.

A lei $n^{\circ}$ 6.766/79 foi flexibilizada pela lei $n^{\circ} 9.785$, de 29 de janeiro de 1999, que reduziu as exigências para parcelamentos em zonas habitacionais de interesse social (ZHIS), excluindo da infraestrutura básica a iluminação pública e a pavimentação. A alteração buscou reduzir os custos na viabilização do parcelamento do solo para os mais pobres.

A partir de 2008, com os avanços das políticas públicas, com programas de incentivo à construção de moradias populares para famílias de baixa renda, 0 tema da habitação social voltou a ganhar importância (TEIXEIRA et. al., 2017). 
A Lei $n^{\circ} 11.977$ de 2009 que regulamentou o Programa Minha Casa Minha Vida (PMCMV) define ZEIS como "parcela de área urbana instituída pelo Plano Diretor ou definida por outra lei municipal, destinada predominantemente à moradia de população de baixa renda e sujeita a regras específicas de parcelamento, uso e ocupação do solo". Portanto, são zonas que integram o perímetro urbano e devem possuir infraestrutura e serviços urbanos ou garantir a viabilidade de sua implantação (MINISTÉRIO DAS CIDADES, 2006, p. 15).

A criação de ZEIS é um importante instrumento para a viabilização do acesso à terra urbanizada pelos mais pobres e também para a produção da HIS. A implementação de ZEIS pode envolver diferentes agentes nos municípios: movimentos sociais de moradia, entidades profissionais, construtoras e universidades.

A lei federal $n^{\circ} 11.888$ de 24 de dezembro de 2008 (Lei de Assistência Técnica em Habitação de Interesse Social - ATHIS) criou instruções legais para a atuação de arquitetos e urbanistas. Em seu artigo $1^{\circ}$, estabeleceu o direito das famílias de baixa renda à assistência técnica para o projeto, a construção e a modificação de sua moradia, com objetivo de otimizar e qualificar espaços, além de formalizar a edificação, reforma ou ampliação da habitação.

Em 2018, o Conselho Federal de Arquitetos e Urbanistas incentivou a realização de eventos em diversos estados do país com a temática da atuação profissional em habitação social.

Benetti (2012, p. 7) destaca a importância e responsabilidade das universidades no ensino de projeto da habitação social, assim como em criticar, denunciar e propor alternativas para a moradia das camadas populares.

Neste contexto, a disciplina de Ateliê de Projetos Integrados em Arquitetura, Paisagismo e Urbanismo I do curso de Arquitetura e Urbanismo da Universidade Vila Velha (UVV), estado do Espírito Santo, tem como temática a habitação social inserida em uma área de intervenção consolidada. A metodologia para o desenvolvimento dos projetos utiliza conceitos relativos à proposta de criação de ZEIS em área consolidada, parcelamento do solo urbano para moradia social, tipologias habitacionais e habitação evolutiva flexível.

A resposta à problemática da habitação social passa por uma ampla e complexa discussão que deve envolver diferentes profissionais, entidades e instituições, dentre eles as Universidades, que possuem um grande papel, que é a formação dos profissionais habilitados a atuarem nesta problemática. Os arquitetos e urbanistas, ao longo da história tiveram um papel relevante. A formação na graduação deve ter este debate e ensino, tendo em vista as especificidades e restrições de produzir habitação social.

\section{METODOLOGIA}

O tema da disciplina de Ateliê de Projetos I é a habitação de interesse social, localizada em uma área urbana consolidada da Região Metropolitana da Grande Vitória/ES, servida de infraestrutura urbana e transporte público; enfim, inserida em um contexto de possibilidade na cidade, que permita a inserção social efetiva de seus usuários. 
A metodologia é organizada nas seguintes etapas: fundamentação teórica sobre urbanização e habitação social no Brasil; visita à área de intervenção; análise de parâmetros físicos-ambientais e territoriais da área de intervenção (transformada em ZEIS); desenvolvimento de projeto de parcelamento do solo na forma de loteamento destinado à moradia social; fundamentação teórica sobre intervenções paisagísticas em áreas de interesse social (ênfase nos parques lineares); proposta de projeto de um parque linear integrado ao loteamento e área do entorno; projeto de moradia social flexível evolutiva proposta conforme perfil familiar identificado na área de intervenção (os alunos desenvolvem três propostas para a habitação social, partindo de um módulo embrião inicial). Todos os projetos são desenvolvidos em nível de estudo preliminar e anteprojeto.

A fundamentação teórica conceitual é destinada à abordagem históricaconceitual sobre a temática da habitação social e o processo de urbanização no país, com amplo recorte temporal, partindo de 1850 (Lei de Terras) a atualidade, com ênfase nas Políticas Habitacionais e tipologias de HIS produzidas no país (figura 1).

As aulas expositivas $e$ as referências utilizadas permitem aos alunos compreender as formas de provisão da habitação social e assim discutir a relação entre as propostas feitas em momentos históricos distintos e as propostas atuais. Além disso, o aporte teórico possibilita entender de que forma a produção da habitação social foi viabilizada em seus aspectos políticos, econômicos, sociais e urbanos.

Neste âmbito, os alunos são sensibilizados sobre o fenômeno da segregação e exclusão das populações mais pobres do direito à moradia e à cidade e os impactos atuais no meio urbano: déficit habitacional elevado; existência de favelas, aglomerados subnormais, autoconstrução e moradias precárias; ocupações espontâneas, ausência de infraestrutura básica, etc.

Destaca-se também o papel importante dos arquitetos no debate da provisão da moradia e em propor novas formas de habitação de interesse social 


\section{I. HABITAC̣̃̃O SOCIAL}

1946

Criaçāo da Fundaçāo Casa Popular (FCP) para produção de habitaçảo popular.

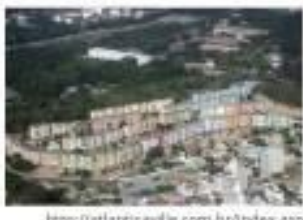

1986

Extinção do BNH e administração dos recursos como responsabilidade da Caixa Económica Federal. Periodo de declínio dos agentes provedores de habitação popular no pais.

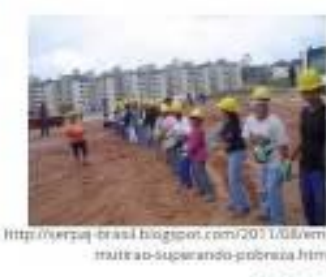

1998

Criação do Projeto Terra, atuando através de intervençőes urbanas em areas de ocupação subnormal.

2009

Entra em vigor o Programa Minha Casa Minha Vida, para a produçẵo de habitação social de mercado.
1937

Atuaçẫo dos lAP's atraves de moradias de aluguel.

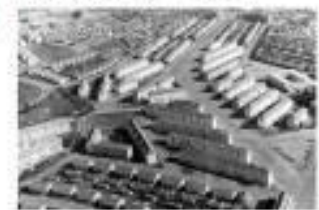

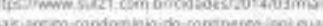
iatedahaterande pe sp

\section{4}

Criação do Banco Nacional de Habitação (BNH) com produçōes de conjuntos habitacionais do tipo COHAB E INOCOOP.

1990

Implementado o sistema de mutirōes comunitários para a construçăo de habitação popular.

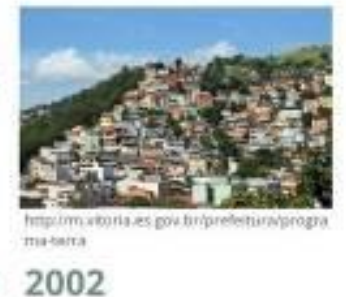

Reformulaçăo do Projeto Terra, o Terra Mais Igual contou com incremento de recursos através do Programa de Aceleraçăo do Crescimento (PAC).

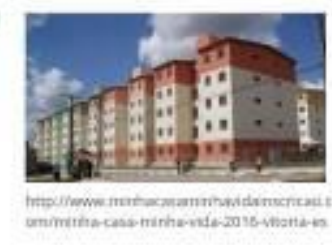

Figura 1 - Abordagem histórica-conceitual Fonte: Autores (2019) 


\section{1 Área de intervenção}

A área de intervenção (gleba) está localizada no bairro de Porto de Santana, localizado no município de Cariacica, um dos sete municípios da Região Metropolitana da Grande Vitória (figura 2).

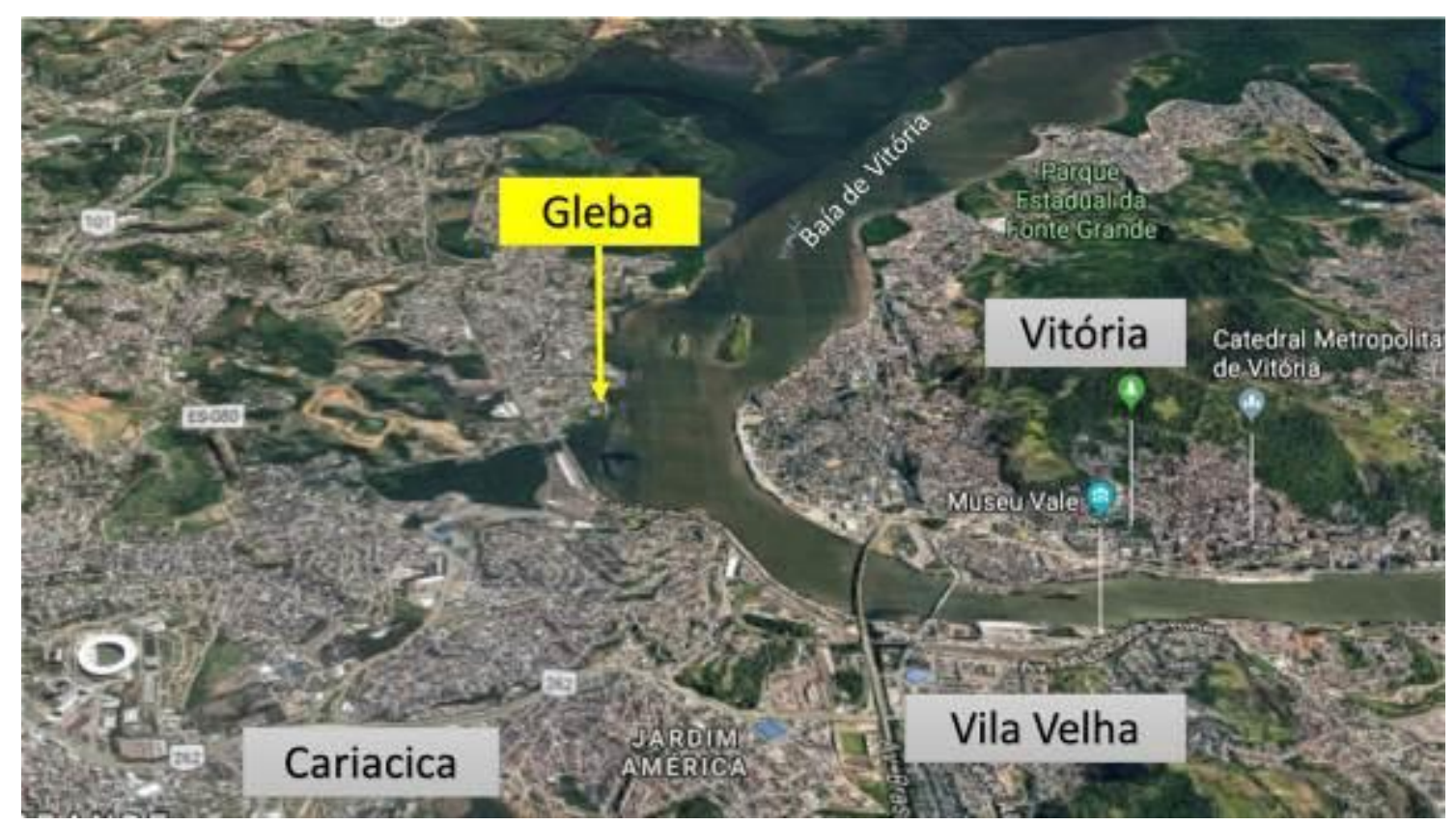

Figura 2 - Área de intervenção

Fonte: GoogleMaps. Montagem dos autores (2019)

Os municípios mais populosos do estado do Espírito Santo e que compõem a Região Metropolitana da Grande Vitória são os que ocupam as quatro posições mais elevadas no ranking de déficit habitacional total do estado, que possui 74.110 famílias nesta situação. Em primeiro lugar está o município da Serra com 15,33\%, seguido de Vila Velha com 11,16\%; Vitória ocupa o terceiro lugar com $8,55 \%$ e Cariacica o quarto lugar com $7,70 \%$ relativo ao total do déficit estadual (IJSN, 2017).

Dados do Instituto Jones dos Santos Neves (IJSN) de 1985 demonstram que o município de Cariacica passou por um processo de urbanização que englobou principalmente loteamentos, invasões e ocupações espontâneas (figuras 3 e 4).
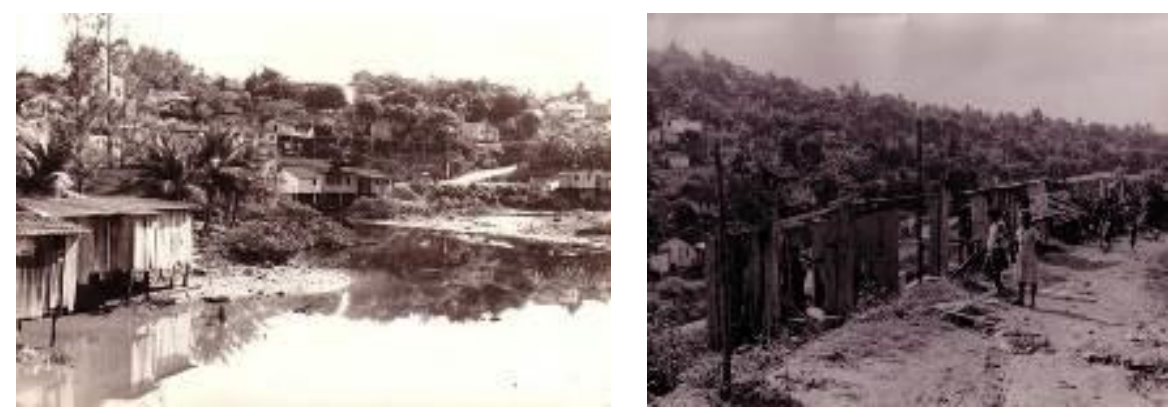

Figura 3 - Construção de barracos em Porto de Santana, Cariacica, 1982 Fonte: IJSN, 1985. Montagem dos autores (2019) 


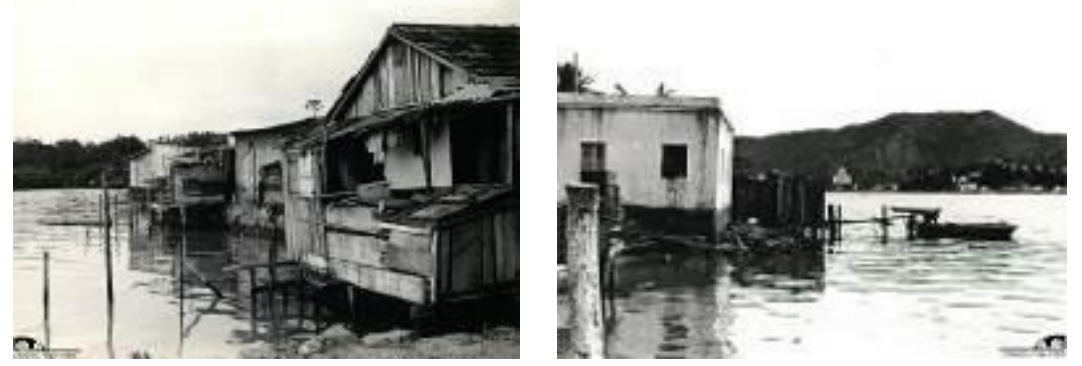

Figura 4 - Ocupações espontâneas e palafitas em Porto de Santana, 1985 Fonte: IJSN, 1985. Montagem dos autores (2019)

No período de 1946 a 1981 haviam 231 loteamentos implantados no município, deste total, oitenta eram loteamentos clandestinos. Atualmente ainda há famílias morando sobre palafitas às margens da Baía de Vitória (figura 5).

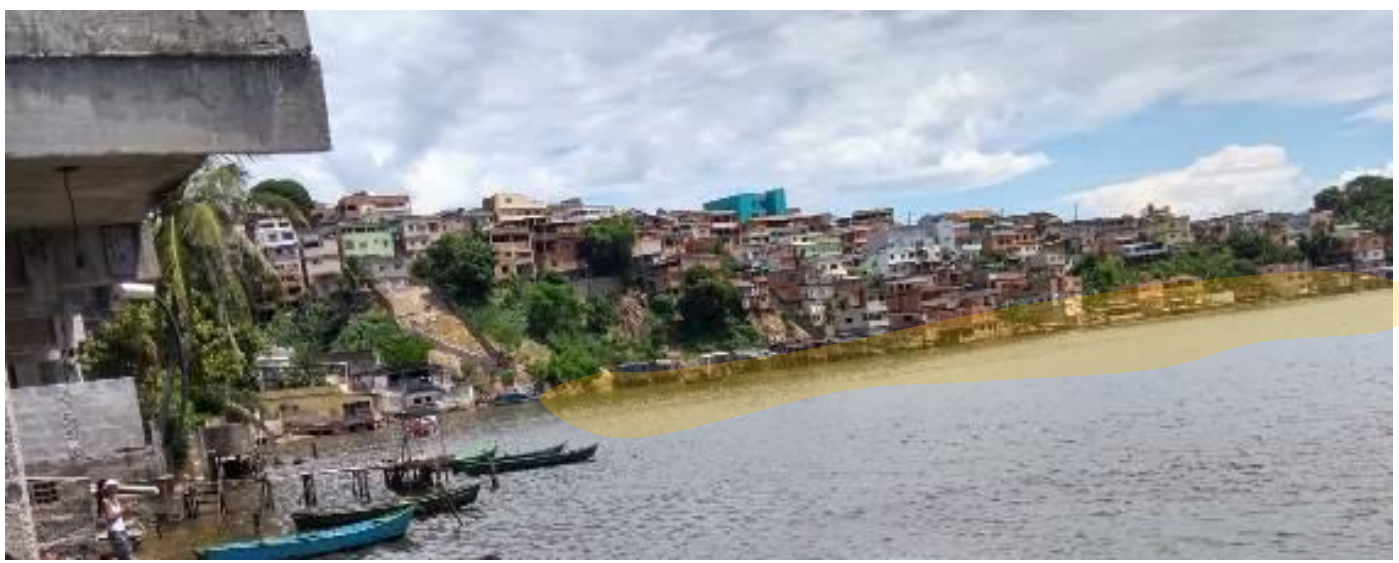

Figura 5 - Cerca de 20 palafitas existentes próximo à área de intervenção

Fonte: Acervo da disciplina (2018)

A região possui infraestrutura urbana e está inserida na malha urbana consolidada, com acesso à transporte público e a $3 \mathrm{~km}$ da capital Vitória. No entanto, é carente de vitalidade e espaços públicos, com forte adensamento, com predomínio do uso residencial e edificações de dois pavimentos (figura 6).
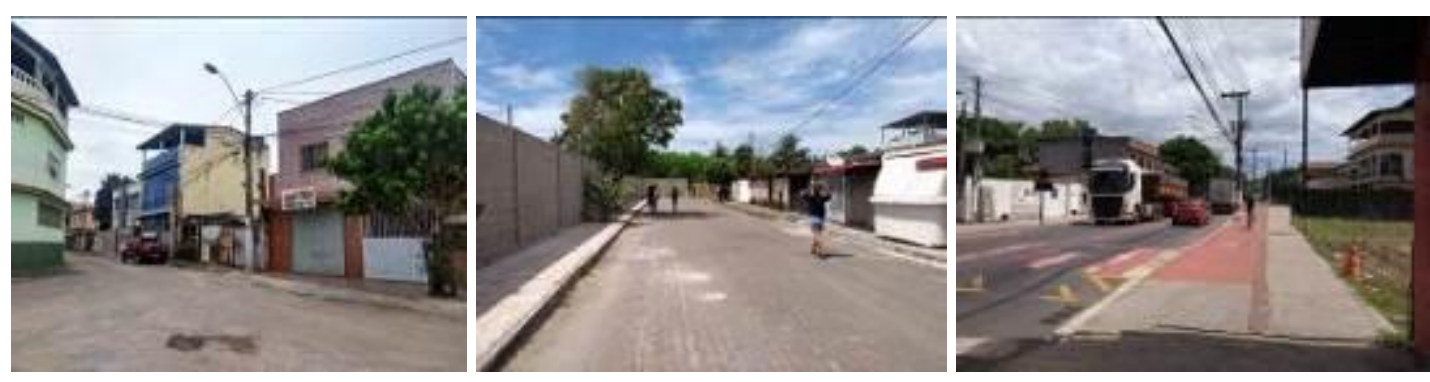

Figura 6 - Vistas de uma das vias que circundam a gleba e seu entorno imediato Fonte: Montagem dos autores (2018)

A gleba, de propriedade privada, possui cerca de 30 mil $\mathrm{m}^{2}$ e está localizada em um bairro com vulnerabilidade social, porém com excelente interesse paisagístico, próximo à uma Baía (mar) e a uma área de proteção permanente (mangue). Além disso, tem forte relação com a pesca, sendo visto na região dezenas de canoas e pescadores que praticam a pesca para subsistência e lazer (figuras 7 a 8). 

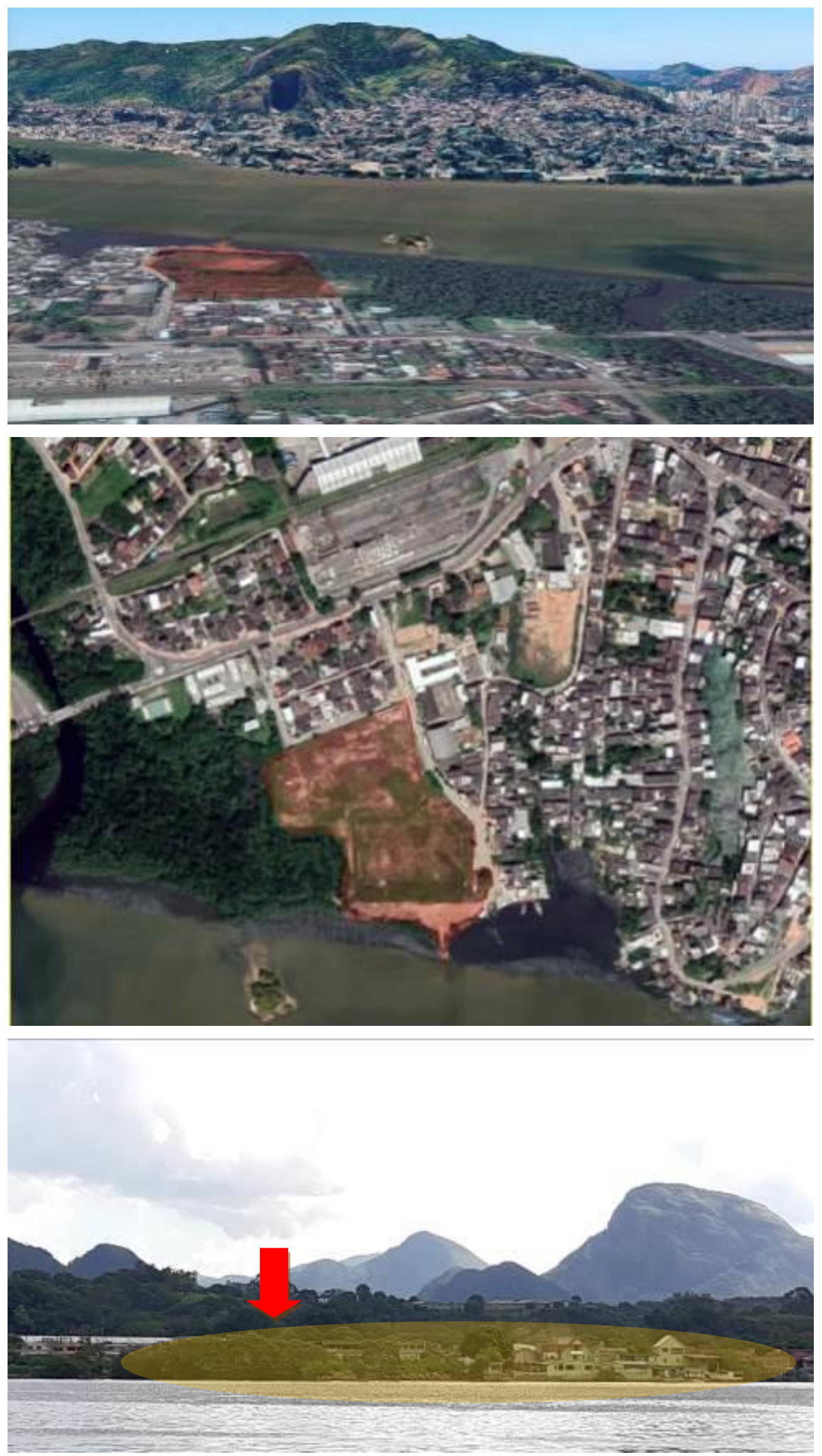

Figura 7 - Vistas da área de intervenção

Fonte: Acervo e montagem dos autores (2018) 


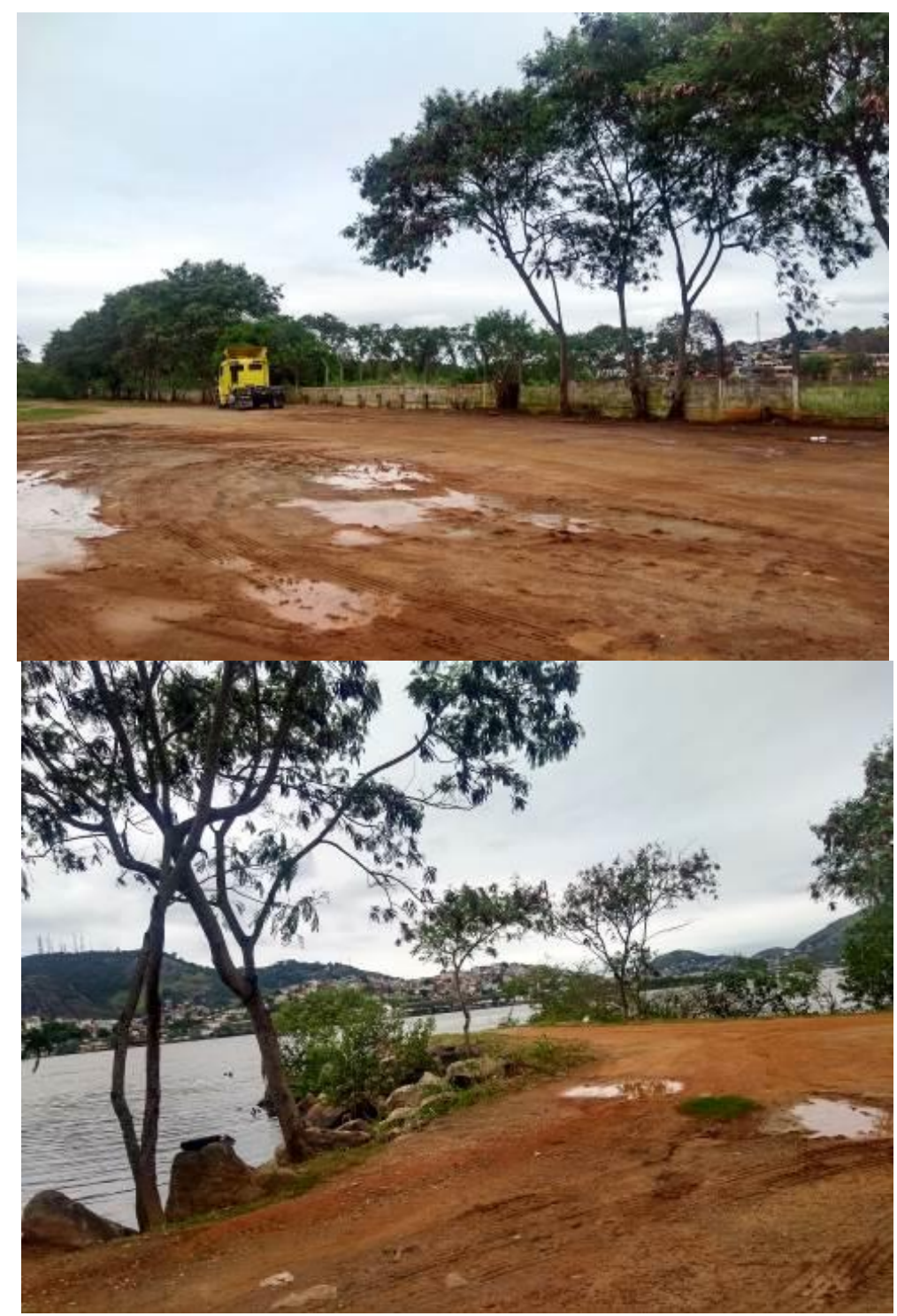

Figura 8 - Vistas da área de intervenção

Fonte: Acervo e montagem dos autores (2018)

A proposta inicial da disciplina para a gleba é a alteração do zoneamento aplicado pelo Plano Diretor Municipal para a área, que possui alto potencial de receber um empreendimento destinado a moradias sociais. A Zona de Ocupação Preferencial, destinada a induzir o adensamento e otimização da infraestrutura municipal é alterada para ZEIS, com o objetivo de lidar com as carências habitacionais do município.

A partir da análise de diferentes Planos Diretores da Região Metropolitana e das características locais da vizinhança, foram definidos os índices urbanísticos a serem aplicados pelos alunos, assim como os gabaritos e as tipologias. A análise das características da área de intervenção, em conjunto com os condicionantes legais (Índices urbanísticos e parâmetros da legislação de parcelamento do solo) norteiam às decisões de projeto dos alunos. A expressão gráfica da percepção dos mesmos sobre a área é expressa através de diagramas (figura 9). 
DIAGRAMA FISICO AMBIENTAL

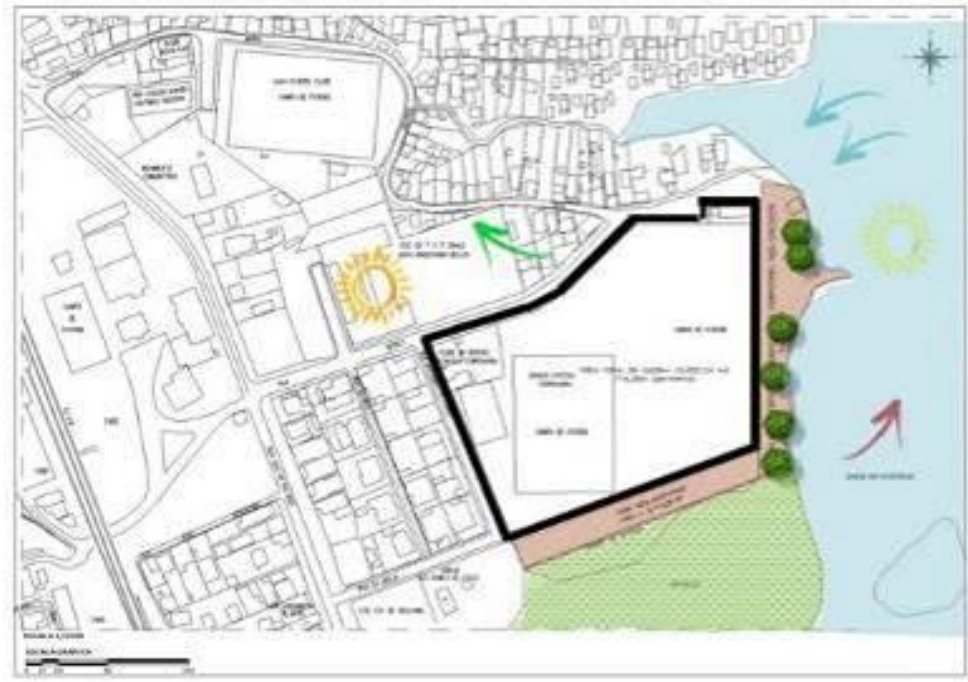

LEGENOA

DIAGRAMA FISICO TERRITORIAL

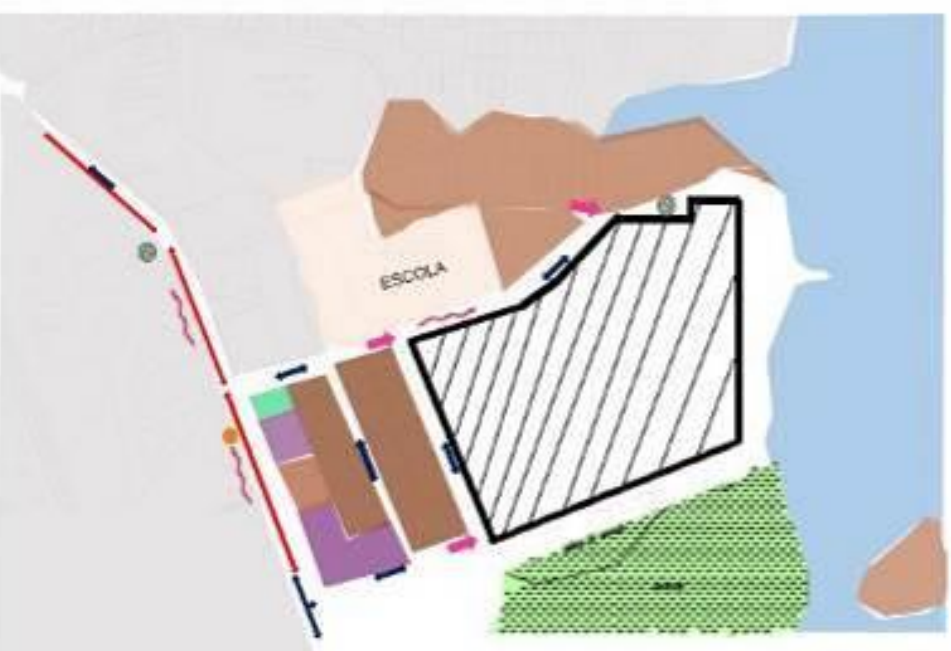

Hereves

SOC DA WANATA

SOL DA TAROE

VENTOS

i2 PMEDONHNANTES

ARECRIZACTIO

LMETE DA QLEBA

\section{MANCUE}

COAPOS D'GLAA

AREANON

AEDIFICANDI

1 Maxcos visunis-

MATCCS VISUA:

MESTRE ALVAFO

D7 arenda Gleba

14 muNGuEZL

$\sim$ muldo

Anill ACESso

$\leftarrow$ vas

(1) panto de OMrus

$\longrightarrow$ ciciona

(8) rescos

MESBENCAL.

a. Msto

CCMercial.

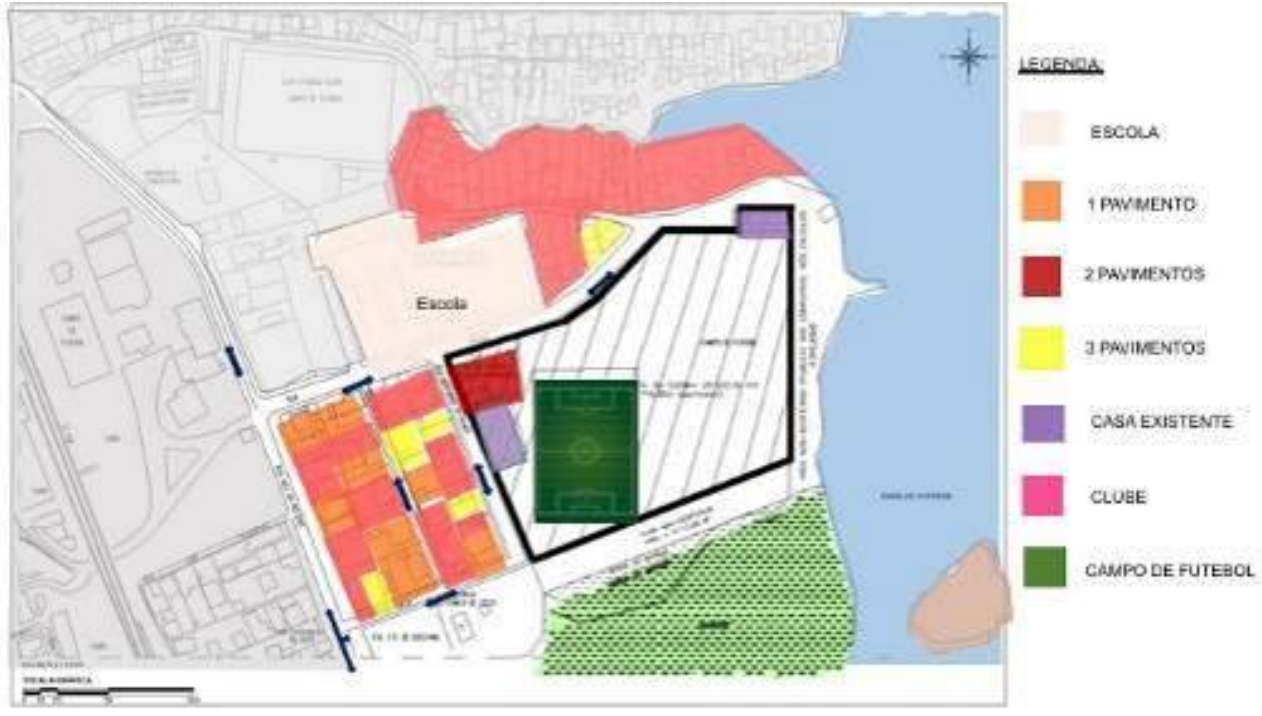

Figura 9 - Diagramas físico-ambiental-territorial

Fonte: Trabalho das alunas Luiza Pessoa, Nathalie Prado, Nicole Schneider e Paula Santos, 2018. Montagem dos autores (2018). 


\section{DESENVOLVIMENTO DOS PROJETOS}

\subsection{Urbanismo e Paisagismo: Loteamento e Parque linear}

A primeira proposta para a gleba é o parcelamento destinado a um loteamento para famílias de baixa renda. Os alunos desenvolvem um projeto de loteamento, em nível de estudo preliminar, para uma área de interesse social, seguindo as seguintes diretrizes: promoção da vitalidade urbana através da proposta e inserção de diferentes usos (unifamiliar, multifamiliar e uso misto); continuidade ao traçado viário existente, promovendo a conexão com as vias locais; adequação do parcelamento aos condicionantes e características locais; valorização da paisagem natural e das visuais; inserção de áreas livres de uso público que promovam a socialização; números de lotes que permitam beneficiar o maior número de famílias possível em diferentes tipologias (casa e apartamento). Um critério muito importante é a existência de no mínimo 20 lotes unifamiliares destinados a abrigar as famílias que moram nas palafitas sob a Baía de Vitória.

Após a definição do projeto de loteamento é proposto o projeto paisagístico do loteamento, com a inserção de um parque linear nos limites com o mangue e o mar. Este tipo de equipamento público visa qualificar a área e a proposta deve promover a identidade local (a pesca), a valorização da paisagem e espaços que promovam diferentes atividades (práticas esportivas, culturais, comerciais, infantis, lazer, estar, contemplação, convivência social, etc).

Para a urbanização do loteamento são aplicados conceitos de infraestrutura urbana conforme sugere os autores Mascaró e Yoshinaga (2005) ao compatibilizar arborização urbana com posteamento público, assim como preservar a caminhabilidade das calçadas com conforto para pedestres e cadeirantes, além de explorar a mobilidade com inclusão de ciclovias, como sugere Jan Gehl (2013); são realizados seminários e oficinas de projeto, mesmo método é aplicado para a concepção do parque linear na gleba de estudo e também na etapa seguinte, para tanto é fundamental a visita de campo.

No parque linear (figuras 10 e 11) os conceitos mais explorados são os estudos das massas verdes, da criação de lugares e caminhos conforme sugere Abbud (2009), marcos e eixos visuais que estimulem a valorização da paisagem e o sentido de orientação e pertencimento ao local (WATERMAN, 2010). 


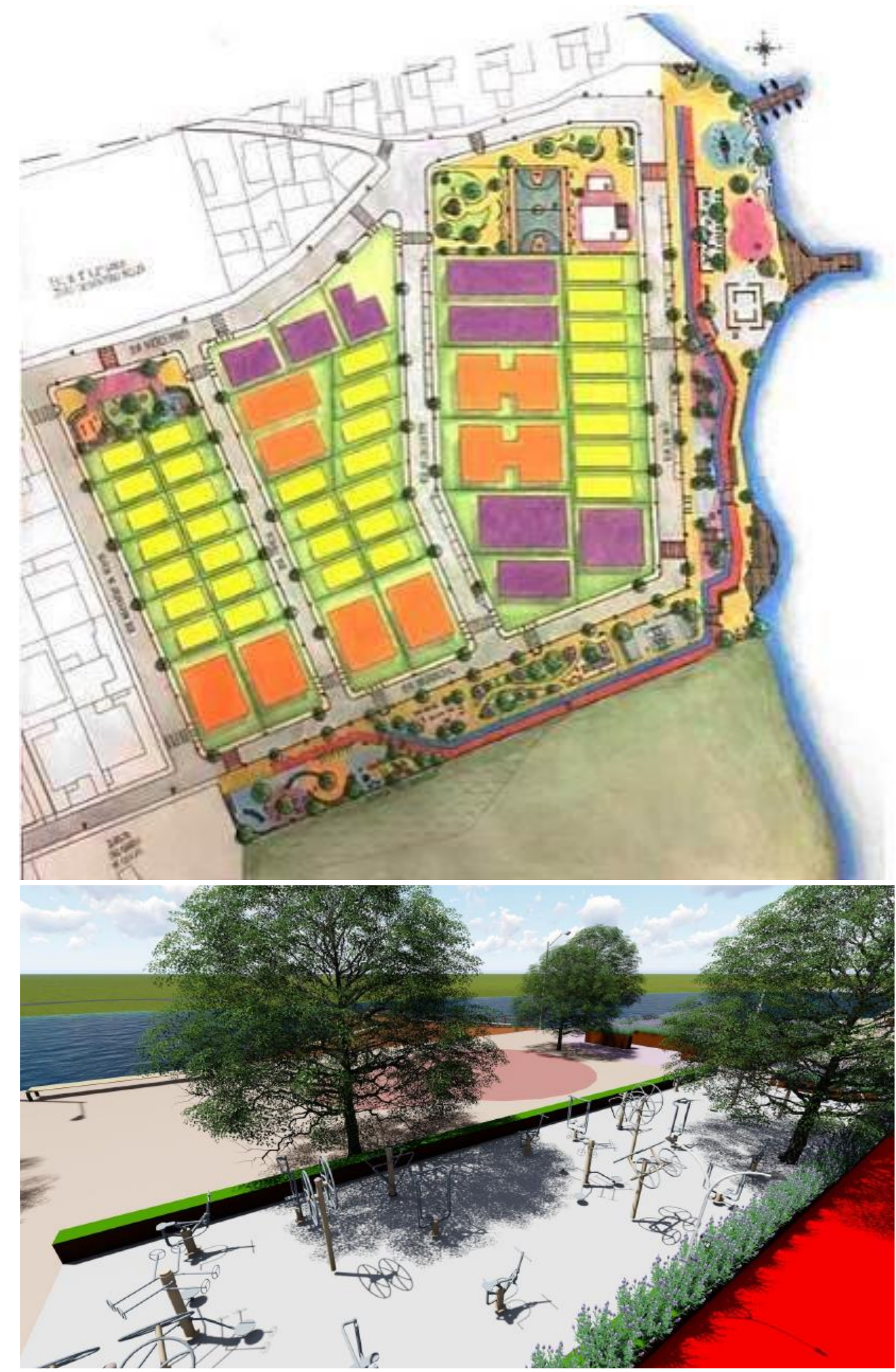

Figura 10 - Etapa 1 paisagismo: humanização do loteamento e parque linear Fonte: Trabalho dos alunos Caio Mulinari, Luana Bassani, Paula Vivas, Thiago de Paula e Yasmin Franco, 2018. Adaptado pelos Autores (2019). 

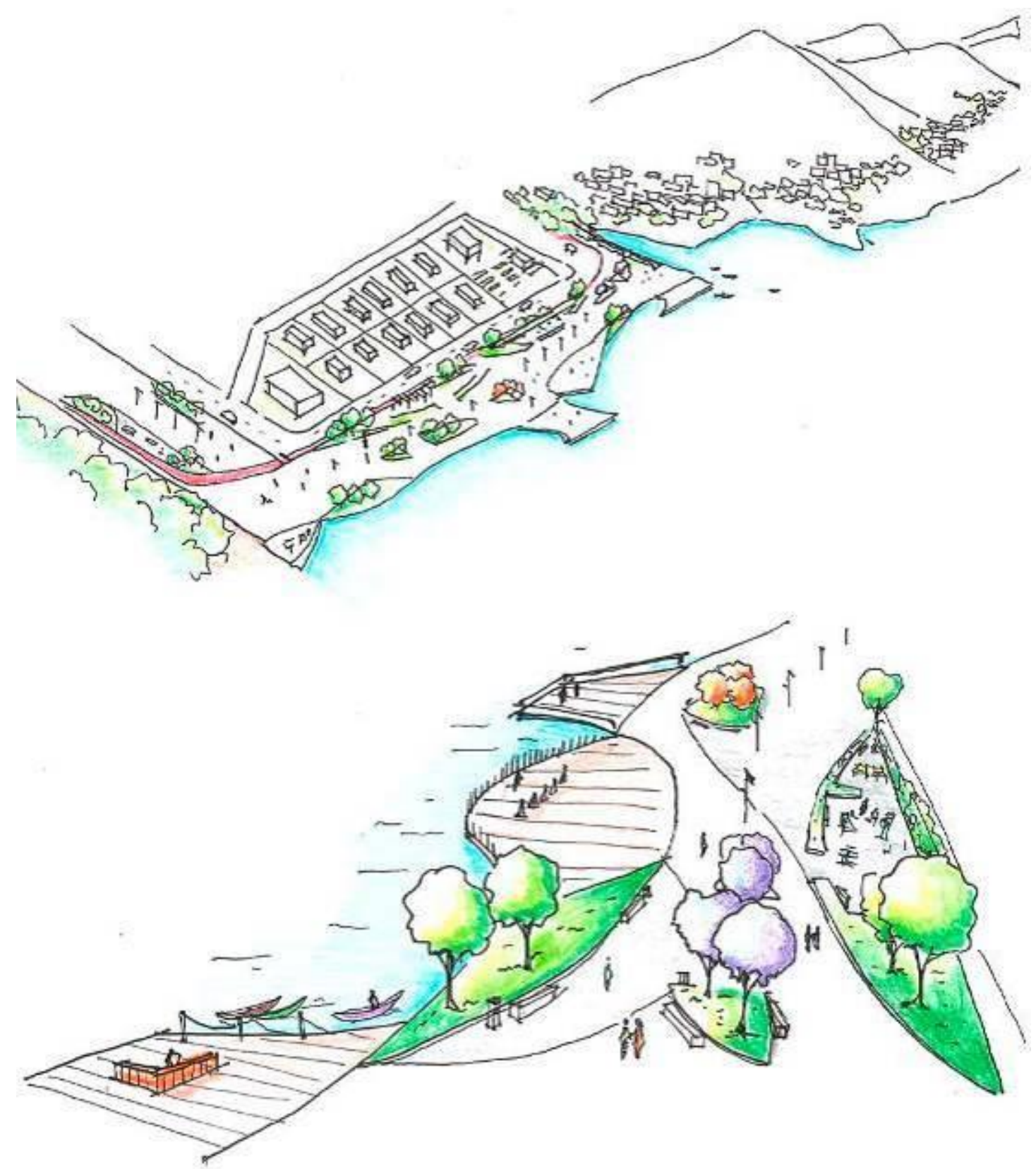

Figura 11 - Etapa 1 paisagismo: vistas do parque linear

Fonte: Trabalho alunos Filipe Marcon, Guilherme Pretti, Julio Henrique, Pedro Caffarello, Rafael Moulin, 2018. Adaptado pelos Autores (2019.

Para a segunda etapa, figura 12, são exploradas as espécies vegetais que melhor se adequam ao clima, favoreçam à manutenção e que correspondam ao volume de massa vegetal esperado conforme projeto das áreas externas da edificação no lote escolhido com oportunidade de se explorar os estilos de jardins, com preferência para o jardim tropical (ABBUD, 2009), devido ao local da área de estudos. Com este processo, consegue-se explorar e aplicar um amplo espectro da arquitetura paisagística, favorecendo o desenvolvimento das habilidades e competências necessárias para a formação técnica do aluno. 


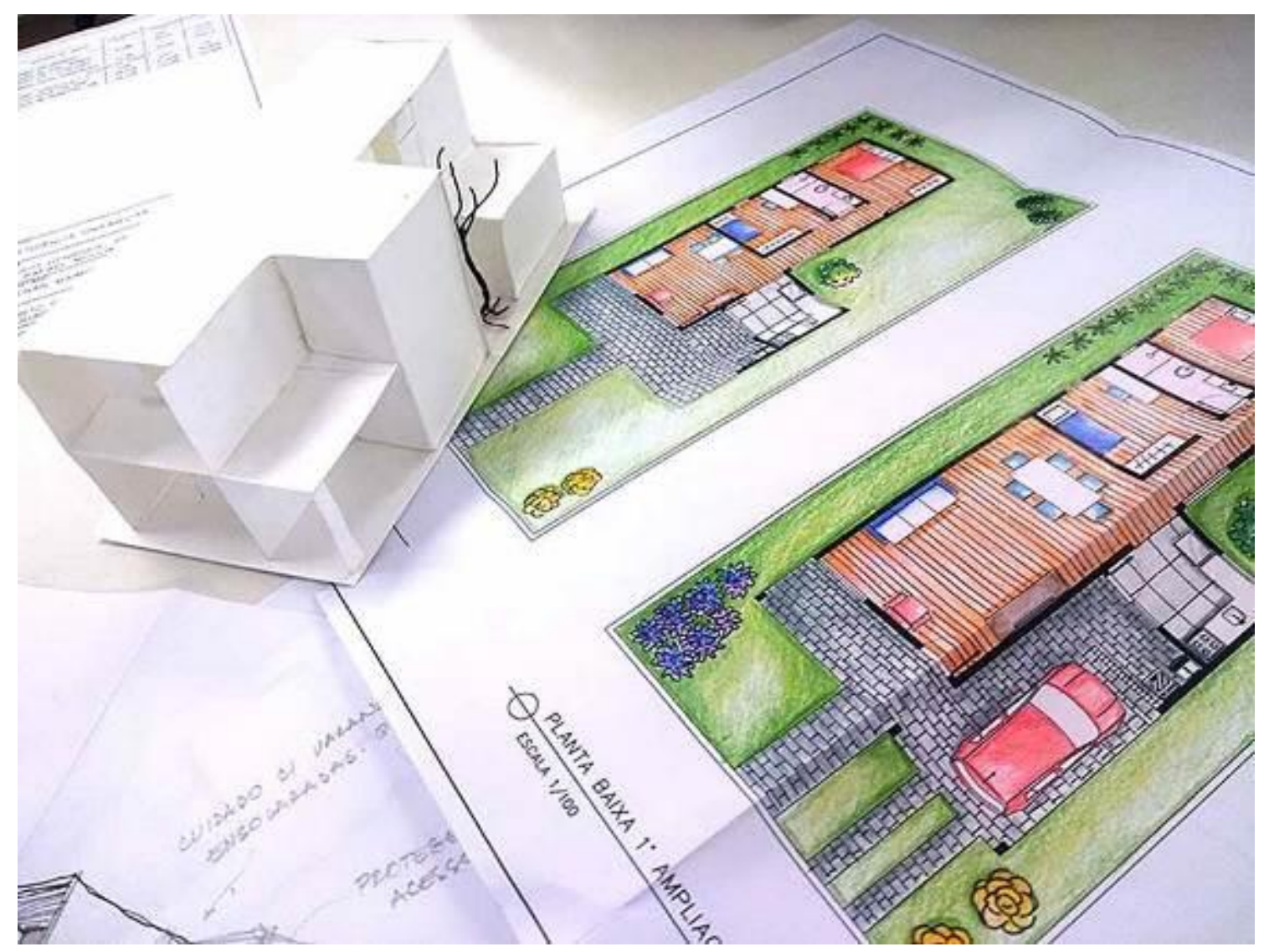

Figura 12 - Etapa 2 paisagismo: jardim área externa

Fonte: Trabalho alunos Julio Henrique, Pedro Caffarello, Rafael Moulin, 2018. Adaptado pelos Autores (2019).

\subsection{Habitação Social Flexível Evolutiva}

Nesta etapa o aluno deve elaborar um projeto arquitetônico de uma Habitação de Interesse Social Evolutiva (HIS-E), destinada a um perfil familiar pré-definido e localizada em um lote unifamiliar do loteamento projetado. Define-se Habitação de Interesse Social Evolutiva a habitação de dimensão mínima que permite modificações que acompanhem as melhorias das condições financeiras e as necessidades de seus usuários ao longo de uma história familiar, ou seja, a condição evolutiva da habitação pode ser identificada como a capacidade que o edifício apresenta de acompanhar a história de uma família (MARTINS et. al, 2013).

Destaca-se, para o aluno, a importância da compreensão do conceito de flexibilidade para o desenvolvimento do projeto da HIS-E, tomando como base a definição colocada por Martins et. al (2013): capacidade do edifício de se adequar a um leque de necessidades específicas, além daquelas necessidades básicas como abrigo, descanso, convívio, etc., a qual passa pela possibilidade de transformação da edificação que, a partir do surgimento da necessidade e na presença de condições financeiras favoráveis, pode ser modificada ou ampliada sem prejuízo da parte pronta, durante ou após a obra.

Dessa forma, segundo os autores, a flexibilidade aplicada ao projeto da moradia é importante para que se possa fazer alterações de arranjos espaciais e usos, sem a necessidade de grandes modificações na edificação original e/ou inviabilização do uso da mesma durante a obra; e a previsão de construção em etapas é uma forma racional de prever, no projeto, para onde 
e como a habitação poderá ser modificada, seja pela criação de novos cômodos, seja pela ampliação dos já existentes (MARTINS et. al, 2013).

Posto isso, são pré-estabelecidas diretrizes para o desenvolvimento da proposta, sendo elas:

- A habitação inicial deverá ser concebida como uma solução "embrião", ou seja, a tipologia da habitação inicial deverá ser uma habitação unifamiliar econômica com área total construída máxima de $55 \mathrm{~m}^{2}$. O projeto deverá ser adequado às necessidades do perfil familiar definido inicialmente;

- Na concepção do projeto da habitação embrião, deverá ser aplicado - conceito de flexibilidade para que a habitação possa evoluir correspondendo às necessidades originadas do perfil familiar (arranjos familiares);

- As propostas de ampliações podem contemplar usos comerciais e serviços (uso misto), uso multifamiliar (coabitação) ou manter o uso unifamiliar somente;

- Na expansão/ampliação deverão ser observados: posicionamento e preservação das áreas úmidas, evitar demolições excessivas e privilegiar acréscimos a demolições, conexão entre setores, etc.

Frente a isso, a partir da compreensão dos conceitos e condicionantes que delineiam o contexto da proposta, embasados pela leitura de textos sugeridos relacionados à habitação social evolutiva e arranjos espaciais flexíveis, os alunos desenvolvem as propostas projetuais.

O aluno inicia a atividade a partir da definição do perfil familiar e o seu ciclo de vida completo. Verificando-se uma crescente alteração no perfil tradicional e o surgimento de novos arranjos familiares, cada equipe deve propor o perfil familiar a que atenderá, assim como o delineamento de seu ciclo de vida, com base nos dados do Censo do Instituto Brasileiro de Geografia e Estatística (IBGE), onde se apresentam os diversos arranjos familiares contemporâneos (Figura 13).

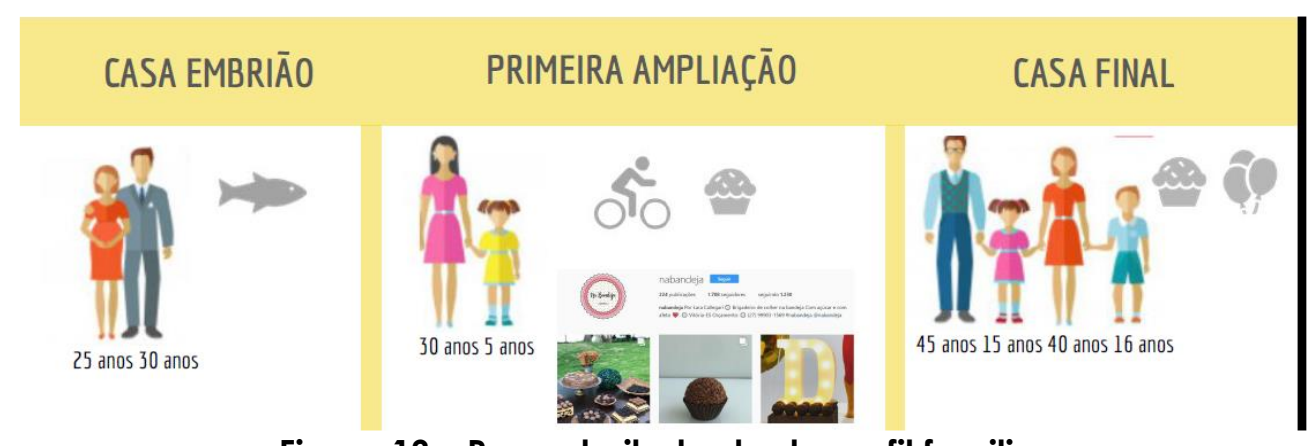

Figura 13 - Proposta ilustrada do perfil familiar

Fonte: Trabalho alunas Giulianna Sangali e Laís Callegari, 2018. Adaptado pelos Autores (2019)

Nessa etapa os alunos devem escolher um terreno parte do loteamento projetado e justificar a sua escolha com base no estudo de seus requisitos ambientais e físicos (índices urbanísticos, topografia, formato, dimensões, acessos, insolação, ventilação, relação de vizinhança, etc.). 
Para o estudo de insolação do terreno, é utilizado o software Analysis SOL-AR 6.2 (LABEEE, 2019), um programa gráfico desenvolvido e disponibilizado gratuitamente pelo Laboratório de Eficiência Energética em Edificações da Universidade Federal de Santa Catarina, que permite a obtenção da carta solar da latitude especificada e a visualização de intervalos de temperatura anuais correspondentes às trajetórias solares ao longo do ano e do dia (

Figura 4).

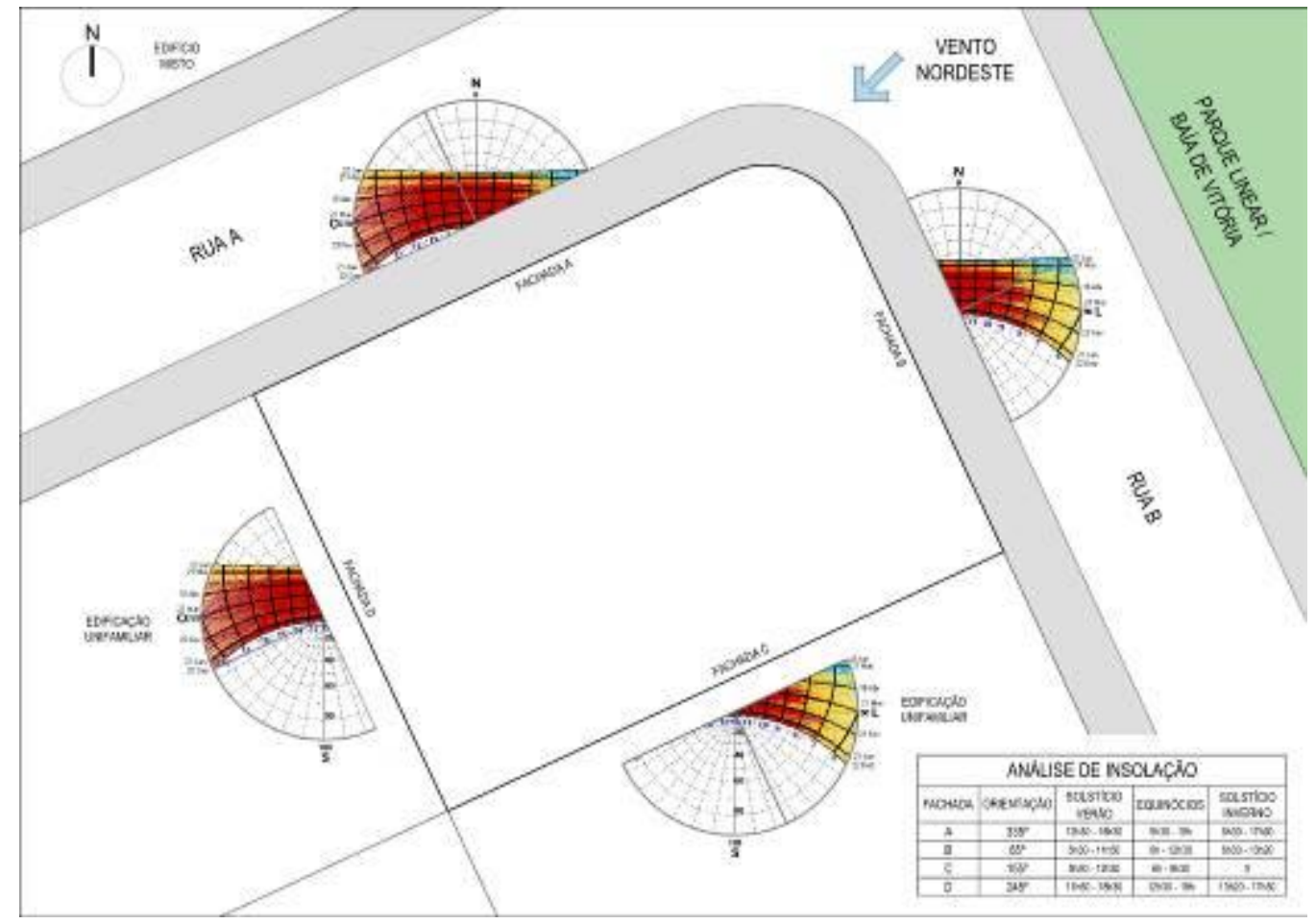

Figura 14 - Prancha modelo de estudo de insolação e análise de condicionantes do terreno.

Fonte: Acervo da disciplina (2018)

Dessa etapa desdobra-se a elaboração do estudo preliminar, em que apresentam as plantas humanizadas de todas as etapas da edificação, bem como perspectivas e quadros de índices urbanísticos, sendo ressaltada a importância da representação gráfica permitir a clara compreensão da evolução do projeto em suas três fases (Figura 15). 


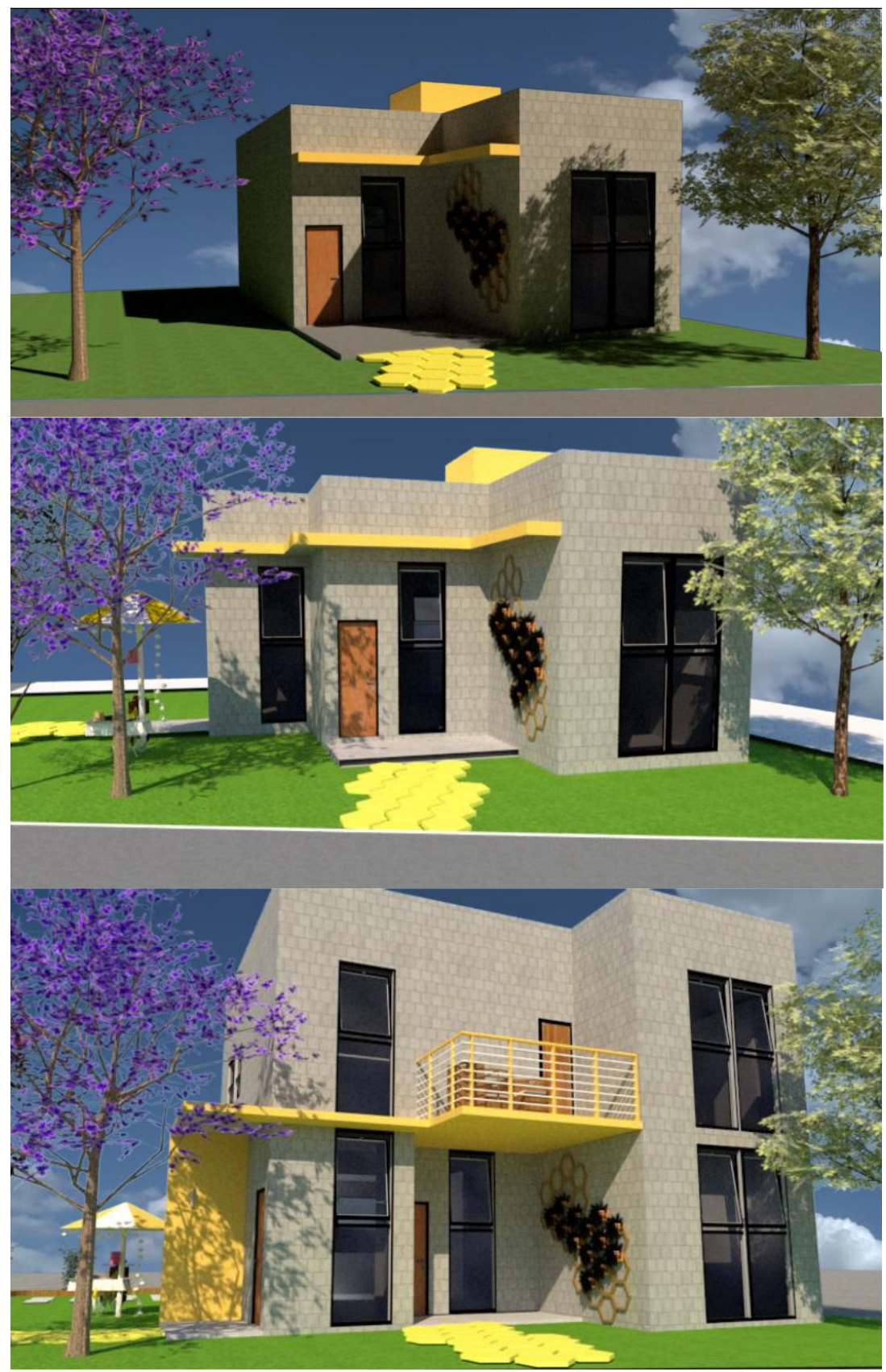

Figura 15 - Proposta de estudo preliminar de uma HIS-E

Fonte: Trabalho alunas Giulianna Sangali e Laís Callegari, 2018. Adaptado pelos autores (2019)

\section{CONSIDERAÇÕES FINAIS}

Benetti $(2012$, p. 15) destaca que o projeto de habitação social é um dos mais difíceis, na medida em que qualquer gesto pressupõe um controle grande de custos e racionalização extrema. Em diversos momentos a habitação popular foi interpretada de fato como habitação pobre, de ideias pobres e de baixa qualidade.

Ao abordar a habitação social, a disciplina de Ateliê I proporciona que o futuro arquiteto tenha a experiência prática para desenvolver esta tipologia habitacional específica, inserida em um contexto urbano de vulnerabilidade social existente. A metodologia da disciplina utiliza técnicas e meios que 
contribuem para que o aluno desenvolva uma consciência social sobre a produção da habitação de interesse social.

\section{REFERÊNCIAS}

ABIKO, A. K. Introdução à Gestão Habitacional. São Paulo: EPUSP, 1995.

Disponível em: Acesso em: 13 mai. 2016.

ABBUD, Benedito. Criando paisagens: guia de trabalho em arquitetura

paisagística. São Paulo: Senac São Paulo, 2009.

ASSOCIAÇÃO BRASILEIRA DE NORMAS TÉCNICAS (ABNT). NBR-1 1.888: Lei de Assistência Técnica. Rio de Janeiro, 2008.

BENETTI, Pablo. Habitação Social e Cidade - Desafios Para o Ensino de Projeto. Rio de Janeiro: editora Rio Books, 2012.

BONDUKI, Nabil. Os pioneiros da habitação social no Brasil: volume 1. $1^{a}$ edição. São Paulo: editora Unesp - edições Sesc, 2014. 387 pag.

GEHL, Jan. Cidades para pessoas. São Paulo: Perspectiva, 2013.

IJSN. Boletim 02: Déficit Habitacional no Espírito Santo com base no CadÚnico. 2017. Disponível em: < http://www.ijsn.es.gov.br/artigos/481 1-deficithabitacional-no-espirito-santo-com-base-no-cadunico-2017>. Acesso em: 10 jul. 2018.

IJSN. Elaboração da política de desenvolvimento urbano para o município de Cariacica: assentamentos urbanos no município de Cariacica. 1985. Disponível em: $<$

http://www.ijsn.es.gov.br/ConteudoDigital/20120810_ij00490_quadrogeraldomu nicipio_versaopreliminar_proj.pdf>. Acesso em: 10 mar. 2019.

LABORATÓRIO DE EFICIÊNCIA ENERGÉTICA EM EDIFICAÇÕES - LABEEE. Software Analysis SOL-AR. Versão 6.2. Santa Catarina: UFSC. Disponível em <http://www.labeee.ufsc.br/downloads/softwares/analysis-sol-ar>. Acesso em 01 jun. 2019.

MARTINS, Marcele Salles; ROMANI Anicoli; MUSSI, Andréa Quadrado, FOLLE, Daiane. Projeto de habitações flexíveis de interesse social. Revista Oculum ens. São Paulo 10 (2), julho-dezembro, 2013. Disponível em <

file:///C:/Users/andreia.muniz.UVV/Downloads/2148-4578-1-SM.pdf>. Acesso em: 15 mar. 2017.

MASCARÓ, Juan Luis; YOSHINAGA, Mário. Infraestrutura urbana. Porto Alegre: Masquatro Editora, 2005.

MINISTÉRIO DAS CIDADES. Guia para regulamentação e implementação de Zonas Especiais de Interesse Social - ZEIS em Vazios Urbanos. Brasília, 2009.

TEIXEIRA, Catharina Christina; et. al. A questão da habitação social no ensino de projeto integrado ao desenho urbano. Arquitextos, São Paulo, ano 18, n. 210.08, Vitruvius, dez. 2017 Disponível em <http://www.vitruvius.com.br/revistas/read/arquitextos/18.210/6818>. Acesso em: 10 mar. 2019.

WATERMAN, Tim. Fundamentos de Paisagismo. Porto Alegre: Bookman, 2010. 